\title{
PEMANFAATAN MATHEMATICAL MORPHOLOGY UNTUK DETEKSI TEPI BATIK
}

\author{
Retno Wahyusari \\ Sekolah Tinggi Teknologi Ronggolawe \\ Email: retnowahyusari@gmail.com \\ Bambang Haryoko \\ Sekolah Tinggi Teknologi Ronggolawe
}

\begin{abstract}
ABSTRAK
UNESCO memberikan empat terhadap beberapa warisan budaya Indonesia, dalam hal ini Wayang Indonesia, Keris Indonesia dan Batik Indonesia. Ketiganya masuk di dalam "The Representative List of the Intangible Culture Heritage of Humanity". Dengan adanya pengakuan UNESCO maka warisan budaya yang telah diakui tidak boleh diakui oleh negara lain. Batik Indonesia merupakan salah satunya maka perlu adanya pendokumentasian motif batik, agar tidak hilang ciri khasnya. Motif batik dapat didokumentasikan berupa gambar atau citra. Motif batik dapat dijaga keaslian motifnya dengan sebuah dokumentasi. Untuk mendapatkan pola batik dilakukan dengan pengolahan citra digital berupa segmentasi citra. Deteksi tepi merupakan masalah dasar yang ada pada computer vision. Tujuan dari deteksi tepi pada citra adalah untuk menandai bagian pada digital image yang intersitas pencahayaannya berubah secara drastic. Peningkatan hasil deteksi tepi dengan menggunakan metode mathematical morphology. Hasil penelitian menunjukan bahwa deteksi tepi metode canny lebih baik dibandingkan dengan metode deteksi tepi yang lain, serta hasil deteksi tepi mampu ditingkatkan dengan menggunakan dilation.
\end{abstract}

Kata kunci: canny, deteksi tepi, dilation, segmentasi citra, UNESCO.

\section{ABSTRACT}

UNESCO gives four against some of the cultural heritage of Indonesia, in this case Wayang Indonesia, Batik Keris Indonesia and Indonesia. All three are entered in "The Representative List of the Intangible Culture Heritage of Humanity". With the recognition of the UNESCO cultural heritage has been recognized may not be recognized by other countries. Batik Indonesia is one of them then the need for documentation of the motif, it is not lost his trademark. The motif can be documented in the form of a picture or image. The motif can be maintained the authenticity motives with a documentation. To get the batik pattern is done by digital image processing such as image segmentation. Edge detection is the basic problems that exist in computer vision. The purpose of edge detection in the image is to mark a section on digital image intersitas lighting changed drastically. Improved results of edge detection using mathematical morphology. The results showed that the canny edge detection method is better than with other edge detection methods, and the results of edge detection is able to be improved by using dilation.

Keywords: canny, edge detection, dilation, image segmentation, UNESCO.

\section{PENDAHULUAN}

Menurut Agung Laksono yang dimuat pada website http://kebudayaan.kemdikbud.go.id mengemukakan empat sertifikat dari UNESCO merupakan simbul pengakuan dunia terhadap beberapa warisan budaya Indonesia, dalam hal ini Wayang Indonesia, Keris Indonesia dan Batik Indonesia. Ketiganya masuk di dalam "The Representative List of the Intangible Culture Heritage of Humanity". Dengan adanya pengakuan UNESCO maka warisan budaya yang telah diakui tidak boleh diakui oleh negara lain. Batik Indonesia merupakan salah satunya maka perlu adanya pendokumentasian motif batik, agar tidak hilang ciri khasnya. Motif batik dapat didokumentasikan berupa gambar atau citra.

Citra atau gambar sebagai salah satu komponen multimedia memegang peranan sangat penting sebagai bentuk informasi visual. Secara harafiah, citra adalah gambar pada bidang dua dimensi [2]. Proses mengubah citra ke bentuk digital dapat dilakukan dengan beberapa perangkat, misal secanner, kamera digital, handycam. Ketika sebuah citra telah diubah kedalam bentuk citra digital, bermacam-macam pengolahan citra dapat diperlakukan terhadap citra tersebut [5]. Pengolahan citra dapat dilakukan berbagai cara diantaranya adalah representasi dan permodelan citra, peningkatan kualitas citra, restorasi 
citra, analisa citra, rekontruksi citra dan kompresi citra. Untuk dapat menjaga keaslian motif batik diperlukan sebuah dokumentasi pola batik itu sendiri. Untuk mendapatkan pola batik dilakukan dengan pengolahan citra digital berupa segmentasi citra.

Segmentasi citra merupakan langkah penting dalam analisis citra. Segmentasi memisahkan gambar menjadi bagian-bagian atau benda. Tingkat yang pemisahan dilakukan tergantung pada masalah yang sedang diselesaikan. Ketika obyek yang menarik dalam aplikasi telah diakses segmentasi harus berhenti. Pilihan teknik segmentasi citra adalah tergantung pada masalah yang sedang dipertimbangkan. Deteksi tepi adalah bagian dari segmentasi citra. Efektivitas pengolahan citra dan computer vision tergantung pada kesempurnaan mendeteksi tepi.

Deteksi tepi merupakan masalah dasar yang ada pada computer vision. Tujuan dari deteksi tepi pada citra adalah untuk menandai bagian pada digital image yang intersitas pencahayaannya berubah secara drastis [2]. Ada banyak teknik deteksi tepi dalam literatur untuk segmentasi citra. Teknik-teknik deteksi tepi antara lain operator Roberts, operator Sobel, operator Prewitt dan operator Canny.

Menurut Senthilkumaran N dan Kirubakaran C untuk meningkatkan kualitas deteksi tepi digunakan metode mathematical morphology. Teknik morfologi awalnya didirikan oleh Matheron dan Serra di tambang Ecoledes [6]. Teori morfologi matematika memprlakukan gambar sebagai set matematika dan transformasi morfologi yang dikembangkan dari Selain Minkowski dan pengurangan didefinisikan untuk mengekstrak fitur dalam gambar [1]. Morphologi adalah teknik pengolahan citra digital dengan menggunakan bentuk (shape) sebagai pedoman dalam pengolahan. Nilai dari setiap pixel dalam citra digital hasil diperoleh melalui proses perbandingan antara pixel yang bersesuaian pada citra digital masukan dengan pixel tetangganya. Operasi morphologi bergantung pada urutan kemunculan dari pixel, tidak memperhatikan nilai numeric dari pixel sehingga teknik morphologi sesuai apabila digunakan untuk melakukan pengolahan binary image dan grayscale image. Operasi morphologi standar yang dilakukan adalah proses erosi dan dilatasi. Dilatasi adalah proses penambahan pixel pada batas dari suatu objek pada citra digital masukan, sedangkan erosi adalah proses pemindahan/pengurangan pixel pada batas dari suatu objek. Jumlah pixel yang ditambahkan atau yang dihilangkan dari batas objek pada citra digital masukan tergantung pada ukuran dan bentuk dari structuring element yang digunakan [7]. Dengan melihat hal tersebut diatas, maka dalam pendokumentasian motif batik dilakukan dengan pemanfaatan mathematical morphology Untuk Deteksi Citra Tepi Motif Batik.

\section{METODOLOGI PENELITIAN}

Pada bab ini membahas tentang tahapan metode penelitian yang dilakukan, dengan tahapan sebagai berikut:

\subsection{Pengumpulan Data}

Pada penelitian ini data yang digunakan adalah citra motif batik yang diambil dari google. Adapun contoh citra yang akan diuji ditampilkan pada gambar 1 berkut ini:
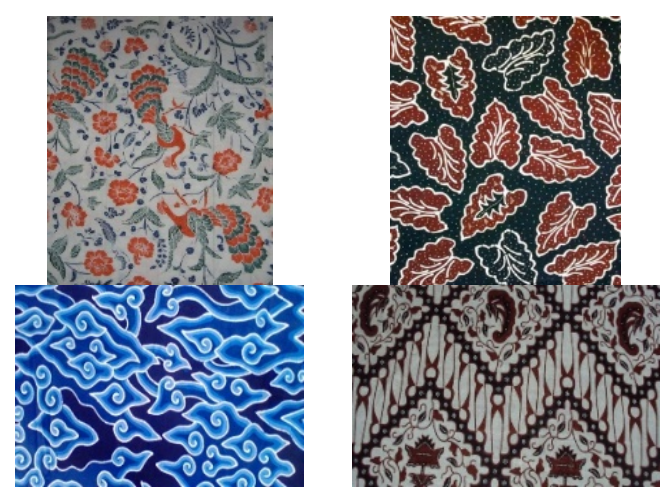

Gambar 1. Citra Asli Diambil dari Google

\subsection{Proses Pengolahan Awal Data}

Dalam proses pengolahan data awal dengan pengumpulan citra uji, kemudian dilakukan merubah citra RGB kedalam bentuk grayscale. 


\subsection{Metode Yang Diusulkan}

Pada tahap ini membahas tentang metode yang diusulkan dalam penelitian yang ditunjukan pada gambar 2 .

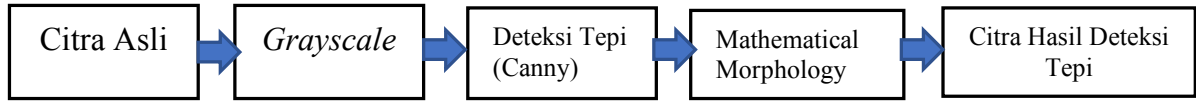

Gambar 2. Metode Yang Diusulkan

\subsection{Eksperimen Dan Pengujian Metode Dengan Menggunakan Matlab R2013b}

\section{HASIL DAN PEMBAHASAN}

Hasil dari penelitian menunjukkan bahwa dengan merubah citra asli kedalam bentuk grayscale kemudian menggunakan deteksi tepi canny dan dipertegas garisnya dengan dilation mampu mendapatkan motif batik yang mendekati motif aslinya. Langkah penelitian dan hasil penelitian sebagai berikut:

\subsection{Merubah Citra Berwarna Kedalam Bentuk Grayscale}

Citra berwarna sebelum diolah lebih lanjut, harus merubahnya kedalam bentuk grayscale. Hasil dari perubahan dari citra berwarna ke bentuk grayscale ditunjukkan pada gambar 3.

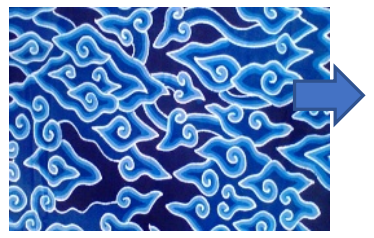

Citra Asli

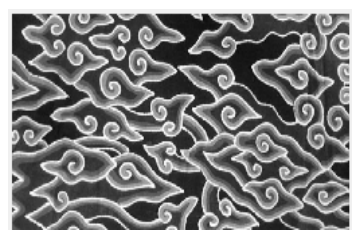

Citra Abu-abu

Gambar 3. Citra Berwarna Dirubah Dalam Bentuk Grayscale

\subsection{Deteksi tepi}

Menurut Muthukrishnan.R and M.Radha[4], deteksi tepi adalah alat fundamental untuk segmentasi citra. Metode deteksi tepi mengubah gambar asli menjadi gambar tepi memanfaatkan dari perubahan warna abu-abu dalam gambar. Operator canny dipilih untuk melakukan deteksi tepi, hal ini berdasarkan pendapat yang dikemukakan oleh John Canny pada tahun 1986 yang menyatakan bahwa operator canny merupakan operator deteksi tepi yang optimal. Hasil deteksi tepi dengan operator canny ditunjukkan pada gambar 4.
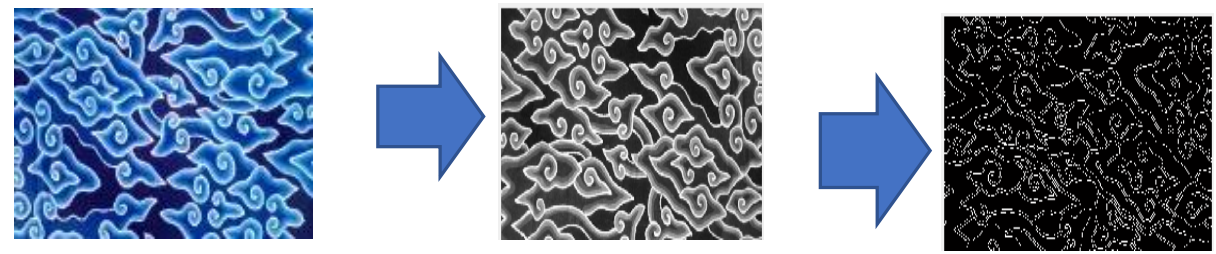

\section{Gambar 4. Gambar Hasil Deteksi Tepi}

\subsection{Mathematical Morphology}

Operasi pada mathematical morphology standar adalah proses erosi (erotion) dan dilatasi (dilation). Peneliti memanfaatkan operasi dilation, penggunaan operasi dilasi biasa dipakai untuk mendapatkan efek pelebaran terhadap piksel bernilai 1. Penambahan operasi dilation mampu memperjelas hasil deteksi tepi yang dilakukan pada tahapan sebelumnya, hasil dari penambahan operasi dilation dapat dilihat pada gambar 5 dan hasil deteksi batik yang diuji dapat dilihat pada gambar 6 dan gambar 7 . 


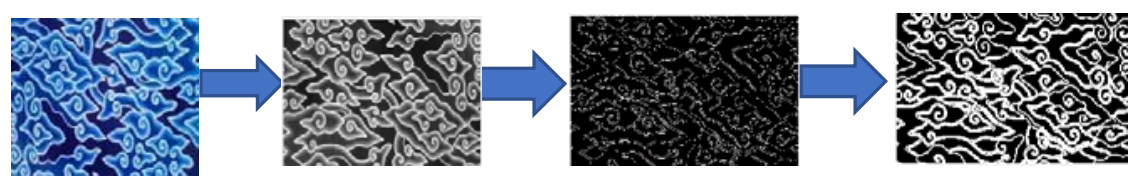

Gambar 5. Hasil Deteksi Tepi Dengan Menambahkan Dilation

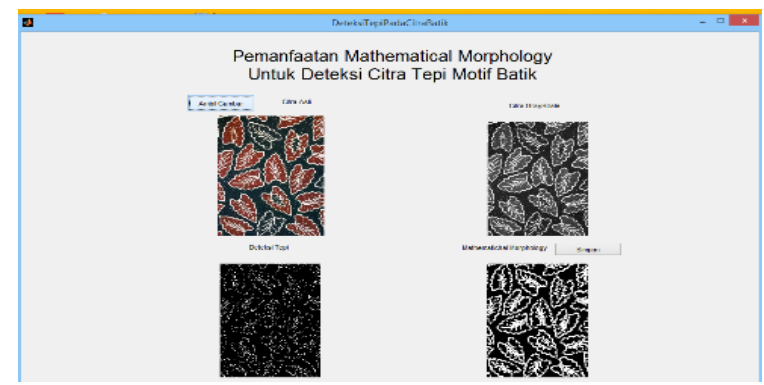

Gambar 6. Hasil Deteksi Tepi Batik Banten

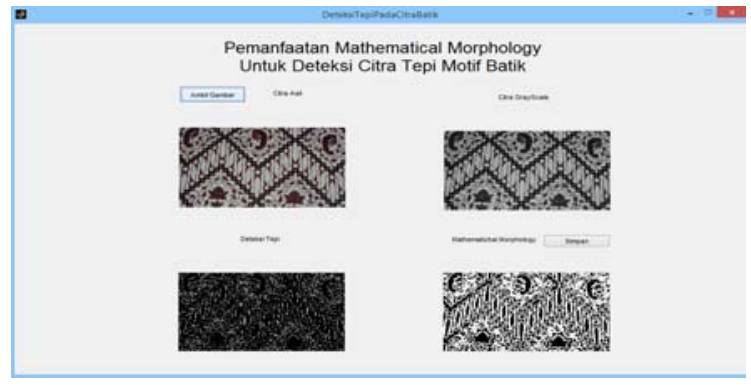

Gambar 7. Hasil Deteksi Tepi Jepara

\section{KESIMPULAN}

Kesimpulan yang dapat diambil adalah:

1) Metode canny lebih baik dalam mendeteksi tepi dibandingkan metode sobel, robet, prewitt.

2) Metode dilasi tepat digunakan untuk memperjelas garis tepi

\section{DAFTAR PUSTAKA}

[1] C. Republic, "Real-Time Scene Text Localization and Recognition,” 2012.

[2] Maini, "Raman Maini, J.S.Sohal, 'Performance Evaluat ion of Prewitt Edge Det ect or for Noisy Images, ' GVIP Journal, Volume 6, Issue 3, December 2006,” vol. 6, no. 3, p. 2006, 2006.

[3] Munir, R, Pengolahan Citra Digital dengan Pendekatan Logaritmik, Informatika, Bandung, 2004.

[4] Muthukrishnan.R, M.Radha, "Edge Detection Techniques For Image Segmentation”, International Journal of Computer Science \& Information Technology (IJCSIT) Vol 3, No 6, Dec 2011.

[5] Rafel C. Gonzalez, Richard E. Woods, Digital Image Processing (Second Edition), Partice-Hall, New Jersey, 2002.

[6] Sumathi C. P., T. Santhanam, and G. G. Devi, "A S Urvey O N V Arious APproaches O F T Ext E Xtraction I N I Mages," vol. 3, no. 4, 2012.

[7] Wirayuda, "Pemanfaatan Operasi Morphologi Untuk Proses Pendeteksian Sisi Pada Pengolahan Citra Digital", Seminar Nasional Sistem dan Informatika 2006; Bali, November 17, 2006. 